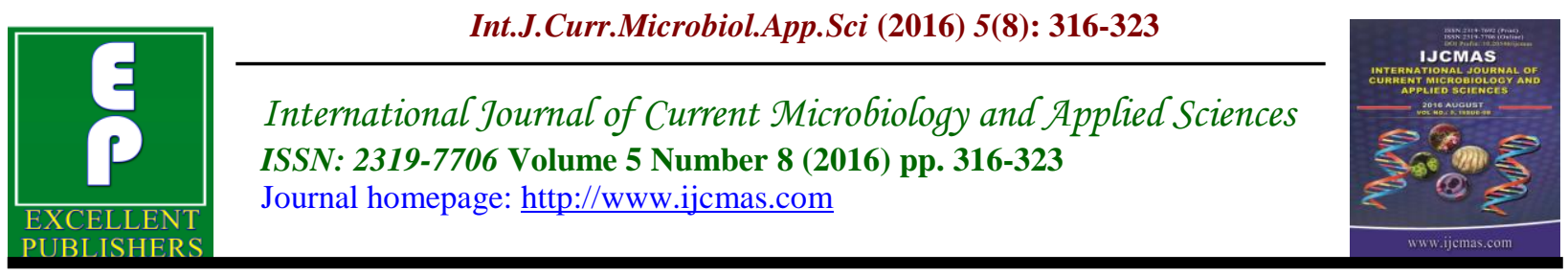

Original Research Article

http://dx.doi.org/10.20546/ijcmas.2016.508.034

\title{
Characterization of Microbial Causative Agents of Subclinical Mastitis in Goats in Bulgaria
}

\author{
Kalin Hristov*, Teodora Popova, Roman Pepovich and Branimir Nikolov \\ Faculty of Veterinary Medicine, University of Forestry, \\ 10 Kliment Ohridski Blvd., Sofia, Bulgaria \\ *Corresponding author
}

\begin{abstract}
A B S T R A C T
Keywords

Goat,

mastitis,

microorganisms,

Staphylococcus

spp.,

mammary gland.

\section{Article Info}

Accepted:

17 July 2016

Available Online:

10 August 2016

Mastitis is the most prevalent mammary gland disease in goats. It has a number of unfavorable health effects in the affected animals and leads to economic losses in the farms. The aim of this study was to isolate and identify microorganisms causing subclinical mastitis (SCM) in goats. Two hundred and twenty-nine milk samples from lactating goats were studied. Microorganisms were isolated from 189 of these samples $(82.53 \%)$, but not from the remaining 40 ones $(17.47 \%)$. Isolation and identification of microbial pathogens was carried out using elective and selective growth media for various groups of bacteria. Identification was done using biochemical tests and additional oxidase and catalase tests. The results showed highest prevalence of Staphylococcus spp. (52.75\%), and particularly, of coagulase-negative staphylococci (CNS). Apart from the samples with a single bacterial species, 42 samples $(23.86 \%)$ were shown to contain different isolates in associations. The most prevalent associations were those of Staphylococcus caseolyticus + S. adjacens and Staphylococcus caseolyticus + Proteus penneri $(9.52 \%)$.
\end{abstract}

\section{Introduction}

Milk produced from goats with mastitis poses a serious veterinary-sanitary and epidemiological hazard. In addition to causing hygiene and health issues, the mammary gland inflammatory processes also cause economic losses due to reduced milk productivity, early culling of animals and treatment costs. Although the microbial pathogens involved in mastitis have been widely studied, they are still focus of research, as the isolated species of etiological agents change over time. Over 100 species of microorganisms are involved in mammary gland inflammatory conditions, although it is about 10 species that are most prevalent. A large number of microbiological studies report staphylococci as the most prevalent mastitis pathogens in goats (Bergonier et al., 2003; Contreras, 2003; Ajuwape et al., 2005; Mhase et al., 2007; Moroni et al., 2007; Byeng et al., 2007; Aydin et al., 200; Islam et al., 2012; Silva et al., 2011; Marogna et al., 2012).

The aim of this study was to isolate and identify microorganisms in milk samples 
from goats with subclinical mastitis from farms in different parts of Bulgaria in order to determine the species composition of the etiological agents.

\section{Materials and Methods}

\section{Milk samples}

Microbiological analysis of 220 milk samples was done to isolate and identify mastitis microbial pathogens in goats. The samples were collected from four farms located in different administrative regions of Bulgaria. In three of these farms, the animals had been given regular immunization against contagious agalactia, but not in the fourth one.

\section{Mastitis tests}

The condition of the udder halves of each goat was examined for subclinical mastitis on site, at the farm, using the rapid mastitis tests CMT-Test (Kruuse, Denmark) and Porta SCC (Porta Check, USA). Direct determination of the somatic cell counts was done by the BDS EN ISO 13366-2/IDF 1482:2006 standard by using Fossomatic (Foss, Denmark) at the National Reference Laboratory for Milk and Dairy Products of the Regional Food Safety Directorate, Sofia.

\section{Isolation procedure}

To isolate and identify the mastitis microbial pathogens, the milk samples were inoculated on elective and selective media for different groups of bacteria and for fungi. Incubation was done at $37^{\circ} \mathrm{C}$ and $28^{\circ} \mathrm{C}$ for $24-72 \mathrm{~h}$ in aerobic conditions. The following growth media were used: Blood Agar, Folate-azide Medium for isolation of enterococci (Bul Bio, NCIPD Ltd, Sofia), Mueller-Hinton Agar and Broth, Eosin Methylene Blue Agar for Gram-negative aerobic and facultative anaerobic bacteria, Cetrimide Agar for isolation of Pseudomonas species; Chapman Stone agar for staphylococci and Sabouraud Agar for fungi (Antisel - Sharlau Chemie S. A., Spain).

\section{Microorganism identification}

Identification of the bacterial isolates was done based on microscopic examination of Gram- and Pfeiffer-stained samples, colony characteristics and biochemical tests using Polymicrotest (Bul Bio, NCIPD Ltd, Sofia), as well as additional oxidase and catalase tests using reagents from Antisel - Sharlau Chemie S. A., Spain. The isolation and identification procedures were done according to Bergey's Manual (Holt et al., 1994).

\section{Results and Discussion}

Microorganisms were identified to be present in $n=189(82.53 \%)$ of the 229 tested udder halves, but not in $n=40$ (17.49\%) of the samples. Of the samples containing microorganisms, $77.78 \%$ gave a singlespecies isolate (monoculture), and $22.22 \%$, multiple species isolates.

The relative prevalence (in percent) of all the microorganisms isolated from the studied samples is shown in Figure 1.

Some of the samples from the farm with no immunization against contagious agalactia were microscopically observed to contain small cells with mycoplasma morphology, most likely Mycoplasma agalactiae. Such cells were observed both in the monoculture and the mixed-culture pathogen isolates.

The prevalence of microorganisms isolated from the samples with mixed infection is presented in Table 1.

The results showed that the prevalent combinations of microorganisms in the 
cases with mixed infections were Grampositive staphylococci with Gram-negative bacteria.

The main direct etiological factors of all types of mammary gland inflammation are different microbial species. Their ability to penetrate and cause inflammation largely depends on the predisposing factors, such as milking and rearing hygiene, individual resistance of the animals, age, lactation period etc.

There are over 30 different species and subspecies of coagulase-negative staphylococci (CNS) (Aarestrup et al., 1999). However, the role of each of them, especially of the non-pathogenic or less pathogenic ones, in the etiology of clinical or subclinical mammary gland infections in goats is still not fully understood. Our results showed that the most prevalent microbial agents of intramammary infections in goats belonged to genus Staphylococcus (52.75\%), particularly to the CNS group. These results are in agreement with previous reports (Contreras et al., 2007; Leitner et al., 2007). Bergonier et al., (2003) also observed $25 \%$ to $93 \%$ prevalence of CNS in different flocks.

In our study, the most prevalent microbial isolate was $S$. caseolyticus. It is, however, not very likely to be definitely considered a single causative agent of subclinical mastitis in goats, since it is mostly isolated in combination with opportunistic Gramnegative bacterial pathogens. It could also be suggested that some opportunistic pathogens, such as intestinal bacteria and Pseudomonas spp., which are more penetrative in the mammary ducts due to their motility, create conditions that favor the association of $S$. caseolyticus. It, in turn, degrades milk casein, creating favorable growth conditions for other non-proteolytic microorganisms, which paves the way for development of inflammatory processes in the mammary gland. Other important causative agents of intramammary infections isolated in our study included CNS members, such as $S$. simulans, $S$. haemolyticus, $S$. hyicus, $S$. caprae, $S$. epidermidis and $S$. saprophyticus. In most cases, they were isolated as single species, which further supports their role in the etiology of mammary gland inflammation. These results are in agreement with the data reported by Deinhofer and Pernthaner (1995) and Moroni et al., (2005), who also identify these microorganisms as main causes of mastitis in goats.

The $3.67 \%$ relative prevalence of $S$. aureus in our study is much lower than that reported by others (Ravnal-Ljutovac et al., 2007; Winter, 2009; Mork et al., 2010). In our study, $S$. aureus was isolated mainly in cases of clinical mastitis and in just a few cases of subclinical infections. Interestingly, Streptococcus thermophilus was isolated from some of our samples. It is well-known to play a role in lactic acid fermentation in the production of some dairy products, as well as to have probiotic properties. It is most probably part of the indigenous udder microflora and could be found in the milk in certain conditions without having a pathogenic role. There is little data about the distribution of Streptococcus adjacens, which was isolated in our study, and its infectious potential in animals. To the best of our knowledge, this is the first study to report a Streptococcus adjacens isolate in Bulgaria. Interestingly, Streptococcus suis monoinfection was also identified in a few samples from one of the farms studied by us. This indicates that there is high potential for easy spread of microorganisms among different animal species reared closely together and demonstrates that this streptococcus could also cause mammary 
gland infections in goats. Another pathogen that most typically affects cows but less commonly causes subclinical mastitis in goats is Streptococcus uberis (Hillerton et al, 1993; McDougall, 1998). Although it is generally not considered typical of goats, it was isolated from $4.13 \%$ of our samples. These results support the findings of other authors that it can play a role in the etiology of intramammary infections in goats, albeit with a lower prevalence (Ameh and Tari, 2000; Lasagno et al., 2012).

Other bacteria that were identified to have a share in the etiology of mastitis in goats were Proteus mirabilis, Proteus penner and Pseudomonas putida with $2.76 \%$, Serratia marcescens with $2.29 \%$ and Enterobacter spp. with $0.92 \%$ prevalence. These microorganisms were rarely isolated as single agents and, due to their lower pathogenic potential, could not be considered among the main causative agents of mammary gland inflammation in goats. In most cases, their role in the etiology of mastitis was in microbial associations with different staphylococci. These minor species have also been isolated in the study of Bedada and Hiko (2011).

Table.1 Microorganisms isolated from the samples with mixed infection.

\begin{tabular}{|c|c|c|}
\hline \multirow[t]{2}{*}{ Microorganisms } & $\begin{array}{c}\text { Number of } \\
\text { isolates }\end{array}$ & $\begin{array}{r}\text { Relative } \\
\text { shares }\end{array}$ \\
\hline & $\mathbf{n}$ & $\mathbf{P}(\%)$ \\
\hline Staphylococcus simulans + Streptococcus thermophilus & 3 & 7,14 \\
\hline Staphylococcus caseolyticus + Micrococcus (Kocuria) kristinae & 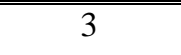 & 7,14 \\
\hline Staphylococcus caseolyticus + Streptococcus adjacens & 4 & 9,52 \\
\hline Staphylococcus caseolyticus + Proteus mirabilis & 1 & 2,39 \\
\hline Staphylococcus caseolyticus + Proteus penneri & 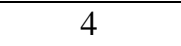 & 9,52 \\
\hline Staphylococcus caseolyticus + Serratia marcescens & 2 & 4,76 \\
\hline Staphylococcus intermedius + Proteus penneri & 2 & 4,76 \\
\hline Staphylococcus caseolyticus + Pseudomonas putida & 3 & 7,14 \\
\hline Staphylococcus intermedius + Pseudomonas putida & 2 & 4,76 \\
\hline Staphylococcus intermedius + Pseudomonas fluorescens & 1 & 2,39 \\
\hline Staphylococcus haemolyticus + Bacillus brevis & 2 & 4,76 \\
\hline Bacillus brevis + Candida albicans & 2 & 4,76 \\
\hline Corynebacterium sp. + E. Coli & 3 & 7,14 \\
\hline Mannheimia haemolytica + E. coli & 2 & 4,76 \\
\hline Enterobacter spp. + Pasteurella multocida & 2 & 4,76 \\
\hline Streptococcus uberis + Staphylococcus epidermidis & 4 & 9,52 \\
\hline Staphylococcus aureus + E. coli & 1 & 2,39 \\
\hline Staphylococcus aureus + Streptococcus uberis & 1 & 2,39 \\
\hline
\end{tabular}


Fig.1 Relative shares of microorganisms causing subclinical mastitis in goats.

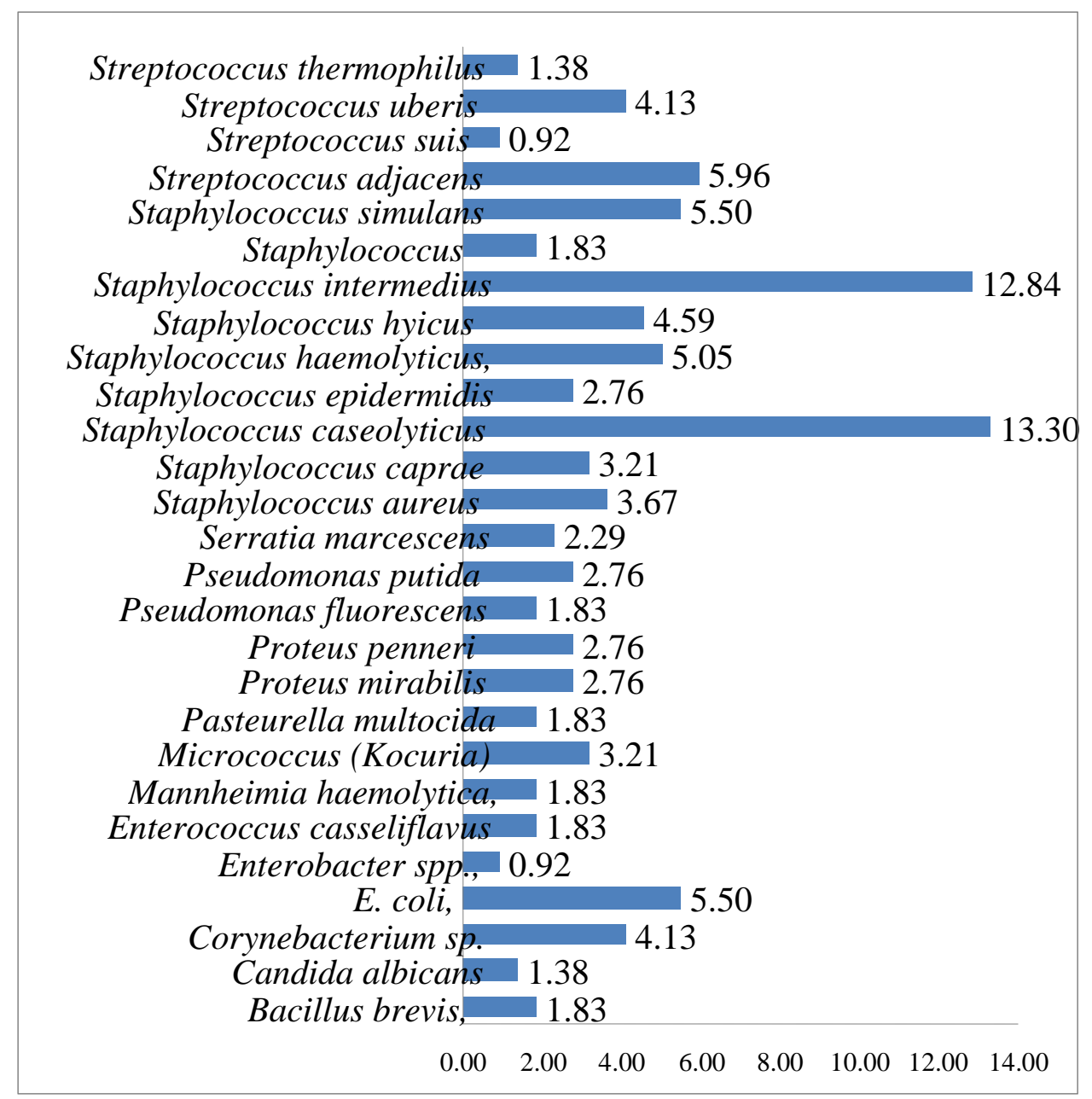

One of the clinically important causative agents of mastitis in goats is $E$. coli. It was isolated in $5.50 \%$ of our samples. Its role has been affirmed in nearly all studies on the microbial etiology of mammary gland inflammations in goats (White and Hinckley, 1999; Ajuwape et al., 2005; Gebrewahid et al., 2012). Highly pathogenic strains can cause severe clinical mastitis, often with a lethal outcome. Although Corynebacterium sp. was isolated from only $4.13 \%$ of the tested samples, mostly in association with $E$. coli, their role in mammary gland inflammation should not be underestimated. This is in accordance with the results reported by Manser (1986),
McDougal et al., (2002) and Bagnicka et al., (2011), who identify them as part of the microbial agents of mastitis in goats.

The small irregular-shaped cells with a brighter central part observed in some of the samples studied by us could most probably be identified as Mycoplasma spp., although additional methods to confirm this were not included in this study. This suggestion is in line with a large number of reports that identify mycoplasma as causative agents of mastitis (Blood et al., 1990; Ameh et al., 1993; Egwua et al., 2001; Anderson et al., 2002). Presence of mycoplasma in milk has also been demonstrated by Kinde et al., 
(1994), who isolated mycoplasma from goat milk from farms with contagious agalactia.

Apart from monocultures, different associations of microorganisms were isolated from $42(23.86 \%)$ of the studied samples. This considerable prevalence among the infected udder halves indicates that mixed infections play an important role in the etiology of subclinical mastitis in goats. Notably, there were mainly different combinations of Gram-positive microorganisms, predominantly staphylococci, with different Gram-negative bacteria. The most prevalent associations were those of $S$. caseolyticus $+S$. adjacens and $S$. caseolyticus $+P$. penneri $-9.52 \% . S$. caseolyticus is not considered as a pathogen and is sporadically isolated from healthy slaughtered lambs, as well as from milk (Fuente et al., 1992). However, our results suggest that, in combination with other microorganisms, it could also take part in the etiology of subclinical mastitis in goats.

Another combination of microorganisms that was isolated by us from a considerable number of samples was that of $S$. intermedius with different Gram-negative species. In $4.76 \%$, it was isolated in combination with $P$. penneri, in the same prevalence, with Pseudomonas putida, and in $2.39 \%$, in combination with Pseudomonas fluorescens. The role of these microbial associations including $S$. intermedius is probably due to the high pathogenic potential of this staphylococcus and the presence of additional microorganisms.

In conclusion, the polymicrobial etiology of mammary gland infections in goats highlights the importance of identification of the microbial causative agents in each individual case. Effective control of mastitis in goat farms would require differentiation of the causative agents and application of effective treatment schemes.

\section{References}

Aarestrup, F.M., H.D. Larsen and N.E. Jensen. 1999. Characterization of staphylococcus simulans strains isolated from cases of bovine mastitis. Vet Microbiol., 66: 165-170.

Ajuwape, A.T.P., Roberts, A.A., Solarin, O.O., and Adetosoye, A.I. 2005. Bacteriological and haematological studies of clinical mastitis in goats in Ibadan, OYO state, Nigeria. 60. 307310.

Ameh, J.A., P.B. Addo, J.O. Adekeye and E.O. Gyang. 1993. Prevalence of clinical mastitis and of intramammary infectionsin Nigerian goats. Prev. Vet. Med., 17: 41士46.

Ameh, J.A. and I.S. Tari. 2000. Observations on the prevalence of caprine mastitis in relation to predisposing factors in Maiduguri. Small Ruminant Res., 35. 1-5.

Anderson, D.E., B.L. Hull and D.G. Pugh. 2002. Diseases of the Mammary Gland. In: Sheep andGoat Medicine, D.G. Pugh ed., W.B. Saunders, Philadelphia, 341-358

Aydin, T. 2009. Identification and antimicrobial susceptibility of subclinical mastitis pathogens isolated from hair Goats' Milk. J. Animal and Vet. Adv., 8(6): 1086-1090.

Bagnicka, E., A. Winnicka, A. Jozwik, M. Rzewuska, N. Strzałkowska, E. Kosciuczuk, B. Prusak, J. Kaba, J. Horbanczuk and J. Krzyzewski. 2011. Relationship between somatic cell count and bacterial pathogens ingoat milk. Small Ruminant Res., 100: 7277.

Bedada, B.A. and A. Hiko. 2011. Mastitis and antimicrobial susceptibility test at Asella, Oromia Regional state. Ethiopia. J. Microbiol. Antimicrobial., 3(9): 228-232. 
Bergonier, D., R. De Cremoux, R. Rupp, G. Lagriffoul and X. Berthelot. 2003. Mastitis of dairy small ruminants. Vet Res., 34: 689-716.

Blood, D.C., J.A. Henderson and O.M. Radostits. 1990. Veterinary Medicine. 8th Edition. ELBS, London. 501 550.

Byeng, R.M., T. Grant and P.H. Steve. 2007. Effect of subclinical intramammary infection on somatic cell counts and chemical composition of goats' milk. J. Dairy Res., 74: 204-210.

Contreras, A., C. Luengo, A. Sánchez and J.Corrales. 2003. The role of intramammary pathogens in dairy goats. Livestock Production Science.Volume 79. Issues 2-3. 273283.

Contreras, A., D. Sierra, A. Sanchez, J.C. Corrales, J.C. Marco,M. J. Paape and C. Gonzalo. 2007. Mastitis in small ruminants. Small Rumin Res., 68: 145153.

Deinhofer, M. and A. Pernthaner. 1995. Staphylococcus spp. as mastitisrelated pathogens in goat milk. Vet Microbiol., 43: 161-166.

Egwua, G.O., J.A. Amehb, M.M. Aliyua and F.D. Mohammeda. 2001. Caprine mycoplasmal mastitis in Nigeria. Small Ruminant Res., 39: 87- 91.

Fuente, R., G. Suarez, J.A. Ruiz Santa Quiteria, H. Meugnier, M. Bes, J. Freney and J. Fleurette. 1992. Identification of coagulase negative staphylococci isolated from lambs as Staphylococcus caseolyticus. Comp. Immunol. Microbiol. Infect. Dis., 15: 47-52.

Gebrewahid, T.T., B.H. Abera and H.T. Menghistu. 2012. Prevalence and Etiology of Subclinical Mastitis in Small Ruminants of Tigray Regional State, North Ethiopia. Vet. World, Vol. 5(2): 103-109.

Hillerton, J.E., M.F.H. Shearn, R.M.
Teverson, S. Langridge and J.M. Booth. 1993. Effect of pre-milking teat dipping on clinical mastitis on dairy farms in England. J. Dairy Res., 60: $31-41$.

Holt, J.G., Krieg, N.R., Sneath, P.H.A.a Staley, J.T., Williams, S.T. 1994. Bergey's Manual of Determinative Bacteriology, 9th Ed. Williams \& Wilkins, Baltimore, MS, USA.

Islam, M.R., M.S. Ahamed, M.S. Alam, M.M. Rahman, T. Sultana, Y.S Roh and B. Kim. 2012. Identification and antibiotic sensitivity of the causative organisms of sub-clinical mastitis in sheep and goats. Pak. Vet. J., 32(2): 179-182.

Kinde, H., Al J. DaMassa, P.S. Wakenell and R. Petty. 1994. Mycoplasma infection in a commercial goat dairy causedby Mycoplasma agalactiae and Mycoplasma mycoidessubsp. mycoides (caprine biotype) J. Vet. Diagn. Invest., 6: 423-427.

Lasagno, M.C., Vissio, C., Reinoso, E. B., Raspanti, $\quad$ C., Yaciuk, R., Larriestra, A.J., Odierno, L.M. 2012. Development of an experimentally induced Streptococcus uberis subclinical mastitis in goats, Vet. Microbiol., 154: 376-383

Leitner, G., U. Merin, Y. Lavi, A. Egber and N. Silanikove. 2007. Aetiology of intramammary infection and its effect on milk composition in goat flocks. $J$. Dairy Res., 74: 186-193.

Manser, P.A. 1986. Prevalence, causes, and laboratory diagnosis of subclinical mastitis in the goat. Vet. Rec., 118: 552-554.

Marogna, G., C. Pilo, A. Vidili, S. Tola, G. Schianchi and S.G. Leori. 2012. Comparison of clinical findings, microbiological results, and farming parameters in goat herds affected by recurrent infectious mastitis, Small 
Ruminant Res., 102: 74-83.

McDougall, S. 1998. Efficacy of two antibiotic treatments in curing clinical and subclinical mastitis in lactating dairy cows. NZ Vet. J., 46: 226-232.

McDougall, S., W. Pankey, C. Delaney, J. Barlow, P.A. Murdough and D. Sruton. 2002. Prevalence and incidence of subclinical mastitis in goats and dairy ewes in Vermont. USA. Small Ruminant Res., 46: 115121

Mhase, P. P., Harne, S.D. and Swyawamhi, P.R. 2007. Antibiogram of Aerobic Bacteria Associated with Goat Mastitis, J. Bombay Vel. Coll., 15: 52 54.

Mork, T., B. Kvitle, T. Mathisen and H.J. Jorgensen. 2010. Bacteriological and molecular investigations of Staphylococcus aureus in dairy goats. Vet. Microbiol., 141: 134-141.

Moroni, P., G. Pisoni, M. Antonini, G. Ruffo, S. Carli, G. Varisco and P. Boettcher. 2005. Subclinical mastitis and antimicrobial susceptibility of Staphylococcus caprae and Staphylococcus epidermidis isolated from two Italian goat herds. J. Dairy. Sci., 88: 1694-1704.
Moroni, P., G. Pisoni, G. Savoini, E. van Lier, S. Acuna, J.P. Damian and A. Meikle. 2007. Influence of estrus of dairy goats on somatic cell count, milk traits, and sex steroid receptors in the mammary gland. J. Dairy Sci., 90: 790-797.

Raynal-Ljutovac, K., A. Pirisi and C. Gonzalo. 2007. Somatic cells of goat and sheep milk: analytical, sanitary, productive and technological aspects. Small Rumin Res., 68: 126-144.

Silva, M.C.A., M.P. Cavalcante, M.G.A.R. Almeida, C.G. Barros, W.L.R. Costa, N.S. Silva and F. Alzamora Filho. 2011. Antimicrobial resistance of bacteria isolated from mastitis milk samples from goats in Brazil. Animal hygiene and sustainable livestock production. Proceedings of the XVth International Congress of the Int. Soc. Animal Hygiene, Vienna. 3: 1419 1422.

White, E. and L. Hinckley. 1999. Prevalence of mastitis pathogens in goat milk. Small Ruminant Res., 33: 117-121.

Winter, P. 2009. Praktischer Leitfaden Mastitis: Vorgehen beim Einzeltier und im Bestand. Stuttgart, Parey, p. 254.

\section{How to cite this article:}

Kalin Hristov, Teodora Popova, Roman Pepovich and Branimir Nikolov. 2016. Characterization of Microbial Causative Agents of Subclinical Mastitis in Goats in Bulgaria. Int.J.Curr.Microbiol.App.Sci. 5(8): 316-323. doi: http://dx.doi.org/10.20546/ijcmas.2016.508.034 